\title{
ABBREVIATIONS OF PRINCIPAL MANUSCRIPTS
}

FIRST SET, IN LARGE FORMAT

A Les éthiques d'Aristote, Brussels, Bibl. Royale Albert Ier, MS 9505-06 (formerly MS 2902)

B Les politiques et le yconomique d'Aristote, France, private collection

SECOND SET, IN SMALL FORMAT

C Les éthiques d'Aristote, The Hague, Rijksmuseum Meermanno-Westreenianum, MS Io D I

D Les politiques et le yconomique d'Aristote, Brussels, Bibl. Royale Albert Ier, MS I I 201-02 (formerly MS 2904) 
